\section{Commentary: Structural solutions for isolated, severe, symptomatic tricuspid regurgitation are eagerly awaited}

\author{
Ramesh Daggubati, MD, ${ }^{\mathrm{a}}$ and \\ Harold G. Roberts, Jr, MD ${ }^{\mathrm{b}}$
}

Tricuspid regurgitation (TR) is among the most commonly detected valvular abnormalities. Some degree of TR on echocardiogram was found in $84 \%$ of the population in the Framingham study, whereas at least moderate TR was noted in $8 \%$ of the overall population. ${ }^{1,2}$ The majority of pathologic TR is functional TR with the common causes being pulmonary hypertension, right ventricular (RV) dysfunction, and volume overload due to an intracardiac shunt. ${ }^{3}$ An increasingly common cause of TR is displacement or injury of the tricuspid valve leaflets by pacemaker or defibrillator leads. Although usually initially asymptomatic, moderate and severe TR are associated with a 5-year mortality of $55 \%$ and $65 \%$, respectively, comparable to many malignancies. ${ }^{4}$

Although surgery for isolated tricuspid valve regurgitation comprises $<15 \%$ of patients undergoing cardiac surgery, it may carry a mortality rate of at least $9 \%$ and morbidity up to $71 \%$, especially when performed as an isolated redo operation following mitral valve surgery. ${ }^{5}$ Understandably, $<0.5 \%$ of the 1.6 million moderate to severe TR patients are treated surgically because most patients are referred late after RV dysfunction or once severe pulmonary hypertension has become evident, often accompanied by hepatic and renal failure.

The tricuspid valve annulus is a complex, elliptical, and nonplanar structure that becomes planar and more circular as the RV dilates. Functional TR is a result of relatively small, otherwise normal leaflets poorly coapting in an often subannular position. In the presence of severe TR, RV, and

\footnotetext{
From the ${ }^{\mathrm{a}}$ Division of Cardiology and ${ }^{\mathrm{b}}$ Department of Cardiovascular and Thoracic Surgery, West Virginia University, Morgantown, WVa.

Disclosures: The authors reported no conflicts of interest.

The Journal policy requires editors and reviewers to disclose conflicts of interest and to decline handling or reviewing manuscripts for which they may have a conflict of interest. The editors and reviewers of this article have no conflicts of interest.

Received for publication July 15, 2020; revisions received July 15, 2020; accepted for publication July 15, 2020; available ahead of print July 19, 2020.

Address for reprints: Harold G. Roberts, Jr, MD, Department of Cardiovascular and Thoracic Surgery, West Virginia University, 1 Medical Center Dr, Morgantown, WV 26506 (E-mail: Harold.roberts@wvumedicine.org).

J Thorac Cardiovasc Surg 2020;160:1476-7

$0022-5223 / \$ 36.00$

Copyright (c) 2020 by The American Association for Thoracic Surgery

https://doi.org/10.1016/j.jtcvs.2020.07.051
}

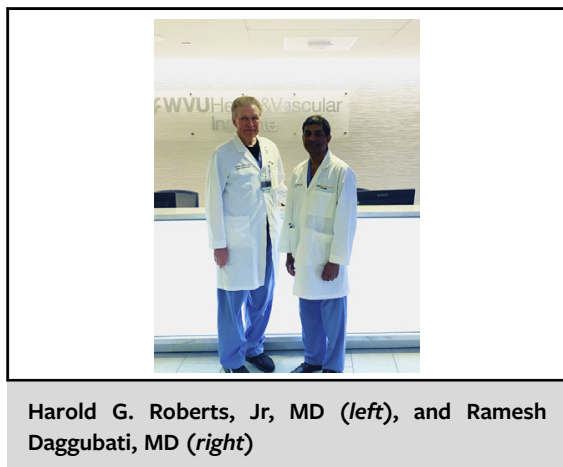

CENTRAL MESSAGE

Effective, durable, structural so-

lutions for tricuspid regurgitation

could potentially save patients

from an inherently high-risk car-

diac surgical procedure.

right atria dilate in response to increasing preload to maintain compliance. ${ }^{6}$ Unfortunately, guidelines do not recommend annual echocardiograms for less than severe TR, often resulting in these patients presenting in the later stages of RV dysfunction.

Donatelle and Ailawadi ${ }^{7}$ provide a concise overview of the transcatheter options for the treatment of TR. Although many of these devices are investigational and following the pathways of percutaneous mitral valve therapies, the main difference will be the high incidence of pacemaker or defibrillator leads that might limit the options in the tricuspid space. Although annuloplasty bands and leaflet repairs have been performed with promising 1-year results, longterm data are awaited before we can draw conclusions as to their value. ${ }^{8}$

The possible benefit of percutaneous therapies for TR is their inherently less invasive approach with potentially lower morbidity and mortality. Their largely investigational status confines their current use in patients with prohibitive risks for surgery. Unfortunately, the delayed recognition of symptoms may limit the success of these devices when used only in patients with severe TR and coexisting extracardiac organ dysfunction. Earlier recognition of RV compliance and dysfunction as well as eventual comparison of repair by surgery versus percutaneous methods is crucial. ${ }^{9}$ Finally, even surgeons actively participating in structural procedures may have somewhat wistfully observed the inexorable replacement of surgical procedures by the catheter, we dare say that few of us would begrudge an effective structural 
solution for our patients experiencing the ravages of isolated, severe TR.

\section{References}

1. Singh JP, Evans JC, Levy D, Larson MG, Freed LA, Fuller DL, et al. Prevalence and clinical determinants of mitral, tricuspid, and aortic regurgitation (the Framingham heart study). Am J Cardiol. 1999;83:897-902.

2. Topilsky Y, Maltais S, Medina Inojosa J, Oguz D, Michelena H, Maalouf J, et al. Burden of tricuspid regurgitation in patients diagnosed in the community setting. JACC Cardiovasc Imaging. 2019;12:433-42.

3. Mangieri A, Montalto C, Pagnesi M, Jabbour RJ, Rodés-Cabau J, Moat N, et al. Mechanism and implications of the tricuspid regurgitation: from the pathophysiology to the current and future therapeutic options. Circ Cardiovasc Interv. 2017; 10:e005043.

4. Nath J, Foster E, Heidenreich PA. Impact of tricuspid regurgitation on long-term survival. J Am Coll Cardiol. 2004;43:405-9.
5. LaPar DJ, Likosky DS, Zhang M, Theurer P, Fonner CE, Kern JA, et al. Development of a risk prediction model and clinical risk score for isolated tricuspid valve surgery. Ann Thorac Surg. 2018;106:129-36.

6. Fukuda S, Saracino G, Matsumura Y, Daimon M, Tran H, Greenberg NL, et al Three dimensional geometry of the tricuspid annulus in healthy subjects and in patients with functional tricuspid regurgitation: a real time, 3-dimensional echocardiographic study. Circulation. 2006;114(1 Suppl):I492-8.

7. Donatelle M, Ailawadi G. Transcatheter tricuspid valve repair: bringing the forgotten valve into the spotlight. J Thorac Cardiovasc Surg. 2020;160: 1467-73.

8. Curio J, Demin OM, Pagnesi M, Mangieri A, Gianini F, Weisz G, et al. Update in the current landscape of transcatheter options for tricuspid regurgitation treatment. Interv Cardiol. 2019;14:54-61.

9. Antunes MJ, Rodríguez-Palomares J, Prendergast B, De Bonis M, Rosenhek R, Al-Attar N, et al. Management of tricuspid valve regurgitation: position statement of the European Society of Cardiology working groups of cardiovascular surgery and valvular heart disease. Eur J Cardiothorac Surg. 2017;52:1022-30.
See Article page 1467.

\section{Commentary: The forgotten valve no longer: But what about the intervention?}

\author{
Vivek Rao, MD, PhD
}

The tricuspid valve is often referred to as the "forgotten" valve, as historically, surgeons have been loath to intervene for a variety of reasons. Beginning with the indications for surgery, the available options, and the long-term results, surgical management of primary or secondary tricuspid valve pathology has been fraught with challenges. ${ }^{1,2}$

The most common pathology for isolated tricuspid disease is infective endocarditis, usually due to intravenous drug abuse. The high rate of recidivism in this population, which portends the risk of converting native valve to prosthetic valve endocarditis, has led to a more conservative approach to this population. Furthermore, the need for

From Cardiovascular Surgery, Room Number 4PMB-457, Peter Munk Cardiac Centre, Toronto General Hospital, Toronto, Ontario, Canada.

Disclosures: Dr Rao is a consultant for Abbott and Medtronic and serves on the North American Surgical Advisory Board for Medtronic.

The Journal policy requires editors and reviewers to disclose conflicts of interest and to decline handling or reviewing manuscripts for which they may have a conflict of interest. The editors and reviewers of this article have no conflicts of interest.

Received for publication May 11, 2020; revisions received May 11, 2020; accepted for publication May 12, 2020; available ahead of print May 25, 2020.

Address for reprints: Vivek Rao, MD, PhD, Cardiovascular Surgery, Peter Munk Cardiac Centre, Toronto General Hospital, 200 Elizabeth St, Toronto, Ontario, Canada M5G2C4 (E-mail: vivek.rao@uhn.ca).

J Thorac Cardiovasc Surg 2020;160:1477-8

$0022-5223 / \$ 36.00$

Copyright (C) 2020 by The American Association for Thoracic Surgery

https://doi.org/10.1016/j.jtcvs.2020.05.038

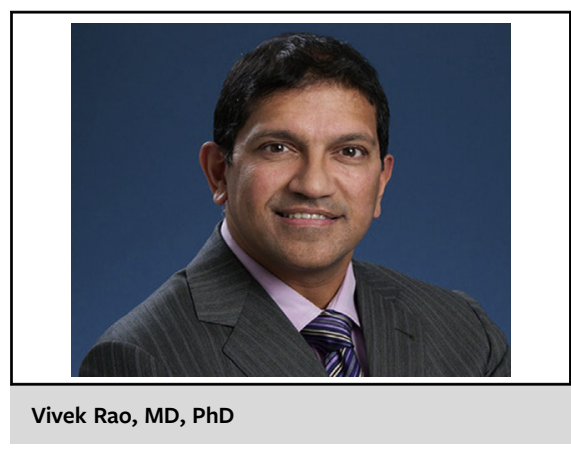

CENTRAL MESSAGE

Percutaneous tricuspid valve therapies will result in greater referrals of patients for heart team assessment. Surgeons should maintain an active role in decision making for this patient population.

formal valve replacement has reduced the enthusiasm for surgical intervention. There is a general, unfounded acceptance that tricuspid valve replacement is associated with poor outcomes. An earlier report from our institution demonstrated an overall survival of $37 \%$ and a conditional survival of $50 \%$ at 15 years in patients receiving either mechanical or biologic valves. ${ }^{1}$ Conditional survival was measured in patients who were discharged from hospital following their index operation. However, few studies 